\title{
Physicians seek business savvy
}

As health-care costs in the United States continue to climb and cost containment becomes a greater concern, physicians are willingly stepping into the business arena. A growing number of established physicians are returning to school to pursue a master's degree in business administration (M.B.A.). A handful of medical schools in the United States are also beginning to offer a new joint degree program, the M.D./M.B.A. The result may be a new class of physicians, equipped with the necessary management skills to take health care in a direction that satisfies cost containment and preserves a high standard of care.

As Stan Bernard, associate principal for the consulting firm A.T. Kearney and M.D./M.B.A. counselor at the University of Pennsylvania, notes, "Physicians traditionally have not been trained in virtually any aspect of business." Bernard believes that this new breed of M.D./M.B.A. physicians will be invaluable in integrating business principles with the practice of medicine.

Students like Jamie Ford, a first-year medical student at Tufts University School of Medicine's M.D./M.B.A. program, currently the only four-year integrated program, feel strongly about the need for trained physicians to be integral players in financial decisions that relate to health care. In addition to seeking a role in health care management or administration, Ford and his classmates plan to practice medicine. Having an M.B.A., Ford hopes, will benefit him in the clinical arena as well, and provide him with the skills to become a better advocate for his patients when he feels that the quality of their care is being sacrificed to financial concerns.

Ray Zollinger, who is currently pursuing an M.D./M.B.A. at the University of Pennsylvania, believes that having an MBA will also help physicians position themselves as cost effective providers and stay economically afloat. In the past "you could be your own independent businessman, make medical decisions, hang up a shingle, and you'd be fine," said Zollinger. But as it becomes economically more challenging to succeed in private practice, understanding the fi- nancial incentives and structure of various health care organizations and networks will be critical for physicians.

Pursuing an MBA, however, may not be the answer for all physicians. Appropriate training for physicians may range from a few classes to a complete M.B.A. degree, says Bernard, depending on a physician's role and extent of involvement on the business side of medicine. What is needed, however, is an integration of a business class into medical school curricula. "I don't think there's any question that there is a tremendous need for more comprehensive health care industry and business training for medical students." Few medical schools offer a comprehensive class of this sort. Jonathan Foster, an M.D. from Columbia University, and second-year business student at the Wharton School of Business at the University of Pennsylvania, agrees that such a class would be useful,

but notes the large amount of material medical students must learn already. "I question whether the schools would be willing to add a substantial course," he said.

Integrating business principles into health care will not be without its obstacles, but M.D./M.B.A.s are a testament to the fact that physicians are willing to adapt and respond to the challenge. Maximizing the benefits from our health-care dollars will depend on increasing productivity, said Bernard Ferrari, M.D./M.B.A. and a Director at the consulting firm McKinsey \& Co. In the strictest of business terms, productivity is a function of inputs and outputs, where the most important input is cost and the most important output is in improved health, as stated by Ferrari. When it comes down to it "medicine is definitely a business," says Zollinger, "[but] it is not a traditional business, because people's lives are at stake."

SHARON KEDAR Houston, Texas

\section{Japan's anti-AIDS drug arsenal slowly expands}

Japan's Ministry of Health and Welfare has approved zalcitabine (ddC) for the treatment of acquired immunodeficiency syndrome (AIDS), thereby increasing the number of anti-HIV drugs available in Japan to only three (the others are AZT and ddI). The decision to grant ddC approval comes just one month after the Japanese government finally agreed on a compensation package (which included new treatment initiatives) for thousands of hemophiliacs infected with HIV in the early 1980s through contaminated blood products (Nature Med. 2, 498; 1996).

The approval of ddC, although welcomed by doctors and patients in Tokyo, has mainly served to underline the need for more anti-HIV drugs, including the new protease inhibitors. Doctors and other medical professionals in Tokyo belonging to the Tokyo HIV Medical Treatment Network are lobbying the ministry to quickly approve 15 different drugs used to treat AIDS-related problems that are already available in the United States. Critics argue that the ministry is being too conservative and not acting quickly enough to make available in Japan drugs that have already been approved in the United States. Even before the HIV contaminated-blood scandal, Japan's drug approval system and the ministry's pharmaceutical affairs bureau were strongly criticized for lacking transparency and acting too slowly.

At the beginning of April, partially in response to the demands of HIV-infected hemophiliacs and their doctors, the ministry designated three drugs - the protease inhibitors ritonavir and indinavir, as well as 3TC - as "orphan drugs," subject to quick screening for approval. Even so, their approval will take at least a year. The ministry also has agreed to give patients greater access to new anti-HIV drugs in clinical trials by allowing pharmaceutical companies conducting trials of AIDS-related drugs to expand the number of patients taking part in Japan.

RICHARD NATHAN Tokyo, Japan 